\title{
EFFECT OF 3D PRINTING DIRECTION ON MANUFACTURING COSTS OF AUTOMOTIVE PARTS
}

\section{Péter Ficzere ${ }^{1}$ \\ ${ }^{1}$ Budapest University of Technology and Economics, Department of Vehicle Elements and Vehicle- Structure Analysis, Hungary}

Received 24 August 2020; accepted 19 December 2020

\begin{abstract}
Additive manufacturing is becoming more widespread in many areas of life, for instance, in the transport industry. One of the main reasons for this is the fact that machines, raw materials, and production are getting cheaper and cheaper. In all cases, the production cost is a driving force of profit, likewise in vehicle manufacturing. The cheaper the technology, the more it spreads. Many factors influence manufacturing costs. One of these is the cost impact of positioning a component's manufacturing position (locating it in the workspace). That is why it has been investigated in the following study. Based on these, the traditional pricing strategy could be simplified. From the results, it could be concluded how economically is worth to place the parts in the working space of the machine.
\end{abstract}

Keywords: costs, variable costs, rapid prototyping, 3D prototyping, automotive parts.

\section{Introduction}

As a result of the proliferation of additive manufacturing technologies (Györi and Ficzere, 2017), more and more people are engaged in either in-house production or payroll printing (Ficzere and Borbás, 2018). In both cases, costs play a significant role. Generally speaking, nowadays, planning time has been significantly reduced, thus reducing time to market (Ficzere et al., 2012). In many cases, it is a significant economic, competitive advantage to be able to enter the market first with a new product (Torok et al., 2018). Volvo engineers recently designed new water pump housing for the company's A25G and A30G articulated hauliers. Engineers used simulation to optimise the design of internal flow passages in the housing but needed to build a prototype to perform functional testing to validate the new design.

${ }^{1}$ Corresponding author: ficzere@kge.bme.hu 


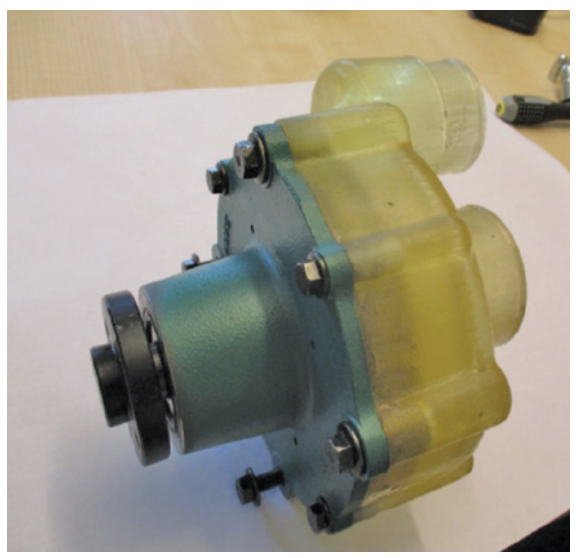

Fig. 1.

Housing Installed on a Water Pump (VCE 3D Printed this Water Pump Housing in Transparent Material for Quick Functional Testing)

Source: (Stratasys, 2020)

Until recently, the Volvo company would have invested in tooling. The tooling cost for this project would have been approximately $\$ 9,090$, with the part cost around $\$ 909$. The lead time for producing the prototype would have been 20 weeks minimum. Since 3D printing the prototype cost $\$ 770$ and took only two weeks, including both design and development, VCE completed its testing much sooner than traditional methods would have allowed. VCE (Volvo Construction Equipment) is now ramping up production of the new part (Hartman, 2019). Formerly referred to as rapid prototypes, $3 \mathrm{D}$ printed products also play a significant role in reducing error costs. An important economic factor, where appropriate, is the area known as rapid tool manufacturing, where prototypes or smaller series require, e.g. the design and manufacture of casting tools are optional. High cost and time savings can be achieved for individual pieces or small-batch manufacturing due to the abandonment of tool design and manufacturing. Many direct and indirect costs can be saved due to time savings (Ficzere et al., 2013), (Zöldy and Török, 2015),
(Gvozdenović et al., 2005). It should be noted that several workpieces of completely different geometries can be produced at the same time. Narrowing down and detailing the production side, many factors influence costs:

- The procedure is chosen;

- Production time, print speed;

- Placement in the workspace;

- Position, orientation;

- Quantity of support material;

- Type of support;

- Percentage of filling;

- Type of filling;

- Layer thickness;

- Material selection;

- The number of pieces to be manufactured.

Based on all this, it is not surprising that there are several pricing strategies on the market (Andrejszki and Török, 2018). The present study examines the impact of only one of these - position and orientation - on costs. We can find similar studies on other research fields also (Mirosavljević et al., 2010). 


\section{Methodology}

During the test, five simple parts (standard short tensile test pieces) are placed in the workspace in different ways, and the effect of position on costs is examined.
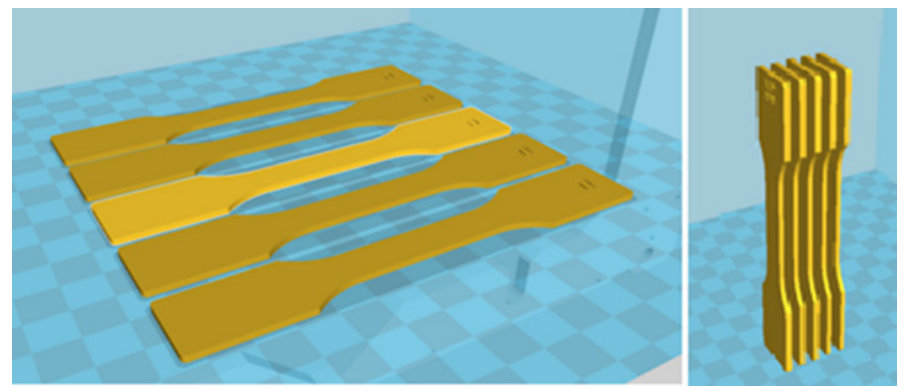

Fig. 2.

Specimens Printed in Laying and Standing Orientation

Different placement methods have different support material requirements (Ficzere, 2020). Also, the machine time required to produce the pieces varies considerably in each arrangement. However, in the oblique position shown in Fig. 3, the use of support is visible (left part of the figure).

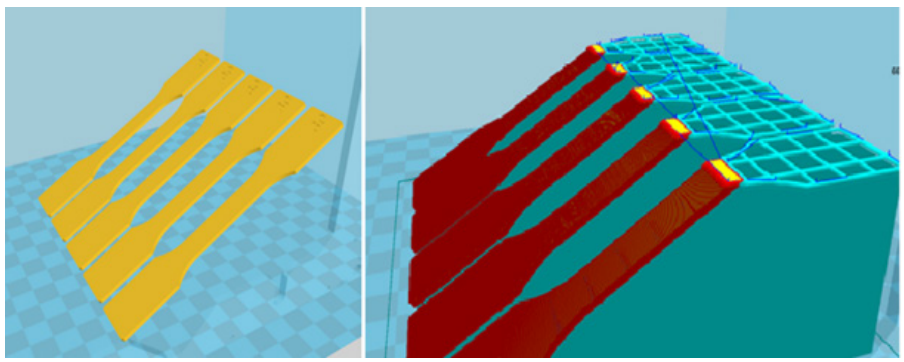

Fig. 3.

Test Specimens Printed at an Angle of $30^{\circ}$

In addition to consuming much material in this case, adequately structured printing of the support material also significantly affects machine time. In this study, we investigate the effect of position on production time and material requirements.

\section{Results}

None of the layouts shown in Fig. 1 requires support, so there is no significant difference in material use, but the vertical arrangement is approx. has double the production time. The production of specimens in oblique, oblique positions requires varying amounts of support materials, which also vary considerably in production time. 


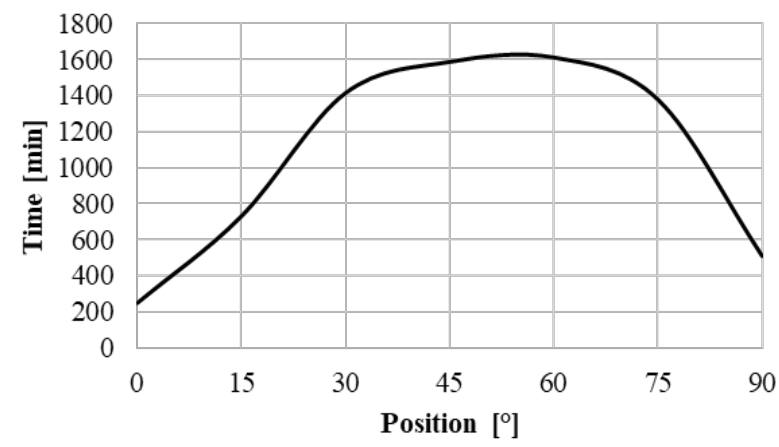

Fig. 4.

Production Time Depending on the Placement Angle

Fig. 4 shows the production time of the specimens as a function of the angle (horizontal) of the pieces. In the same way, we can examine the amount of raw material needed depending on the location.

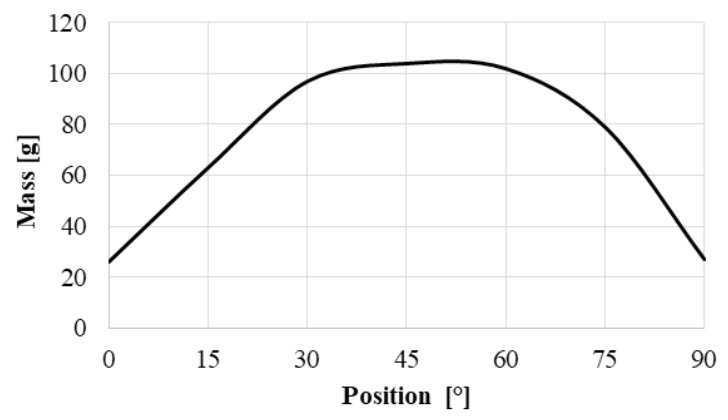

Fig. 5.

Production Raw Material Requirement Depending on the Placement Angle

\section{Analysis}

Examining the diagrams, it is easy to see that the effect of the production position on production time and material requirements is quite similar. It is, therefore, worth examining the relationship between the amount of material used and the production time. 


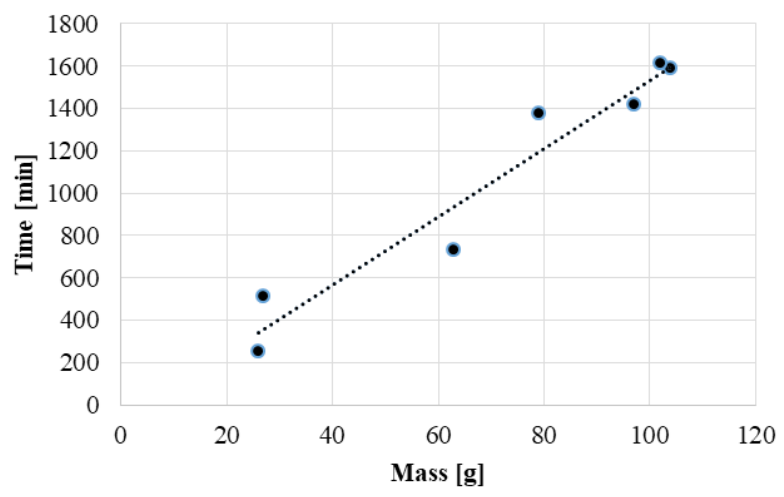

Fig. 6.

Production Time Depends on the Amount of Material Used

The resulting diagram shows that there is an approximately linear relationship between the two parameters.

Fig. 4 and 5 show that horizontal and vertical close layouts are economical in terms of production time and material requirements.

\section{Discussion}

Additive manufacturing companies need to be able to quote the cost of producing the models almost immediately, so complex relationships cannot be used to determine prices. In practice, there are two types of pricing strategies (within a given technology):

- The minimum height of the component;

- Based on the required raw material and production time.

In the first case, the customer can easily calculate the expected price from the geometry of the part. Here, for a given height, there is an amount (with a change in height, the production cost changes linearly), which the manufacturing company has calculated all its costs, benefits.

In the second case, the price is determined by multiplying the unit price per gram of materials by the total amount of material needed, plus the machine overhead. Naturally, the unit cost of materials and the hourly rate of the machine are set by the manufacturer, so that all costs are recouped, and there is some profit.

In both cases, determining unit prices is a serious task that requires experience in economics, business management, and manufacturing. There are other aspects to consider when setting prices, such as uniqueness, emergency surcharge, preand post-processing time, and resource requirements.

Based on these, the following result is obtained in the second case (price based on material and production time). 


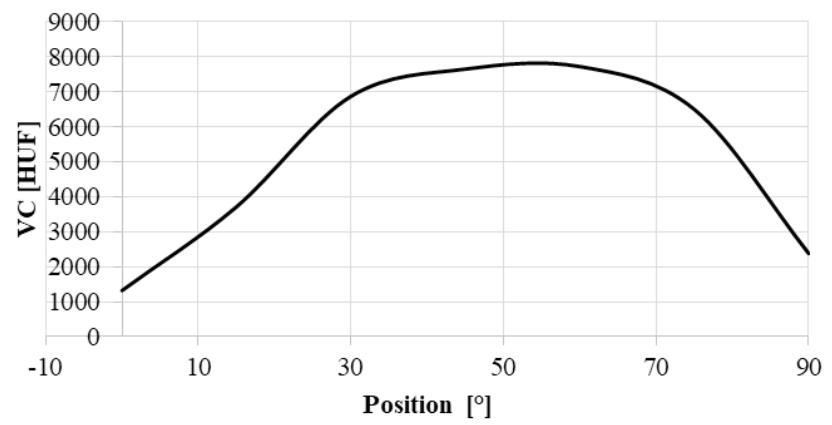

Fig. 7.

Change of Variable Cost (VC) as a Function of Component Position

$\mathrm{VC}=\mathrm{C}_{\mathrm{m}}+\mathrm{C}_{\mathrm{t}}$

(1) This variable cost does not include profit. Material and time cost further analysed

Variable Cost, VC (Variable Cost), can be defined as the sum of Cost of Material $\left(\mathrm{C}_{\mathrm{m}}\right)$ and Cost of Printing Time $\left(\mathrm{C}_{\mathrm{t}}\right)$. In our case $\mathrm{C}_{\mathrm{m}}=12.5 \mathrm{Ft} / \mathrm{g}$ and $\mathrm{C}_{\mathrm{t}}=4 \mathrm{Ft} / \mathrm{min}$.
(Fig. 8). Not surprisingly, this is also quite similar to the weight and production time. It is worth examining the proportion of each cost component:

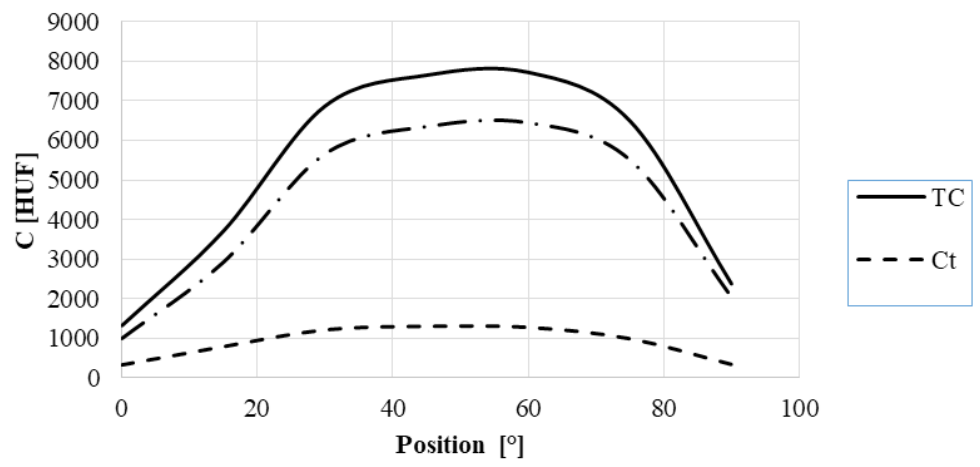

Fig. 8.

Distribution of Variable Cost $(V C)$ by Time-Based Cost $\left(C_{t}\right)$ and Raw Material Cost $\left(C_{m}\right)$ depending on the part position

It can be seen from this figure that at such unit prices, variable costs are more sensitive to time-dependent costs. From the graph in Fig. 7, it could be determined that of the cost components, time-based cost dominates. If we change the unit price based on this, e.g. $\mathrm{C}_{\mathrm{t}}=5 \mathrm{Ft} / \mathrm{min}$, and omitting the required feedstock based component $\left(\mathrm{C}_{\mathrm{m}}\right)$ gives the following diagram. This pricing strategy is also used by the 3DEE company based in Vienna (3dee, 2019). 


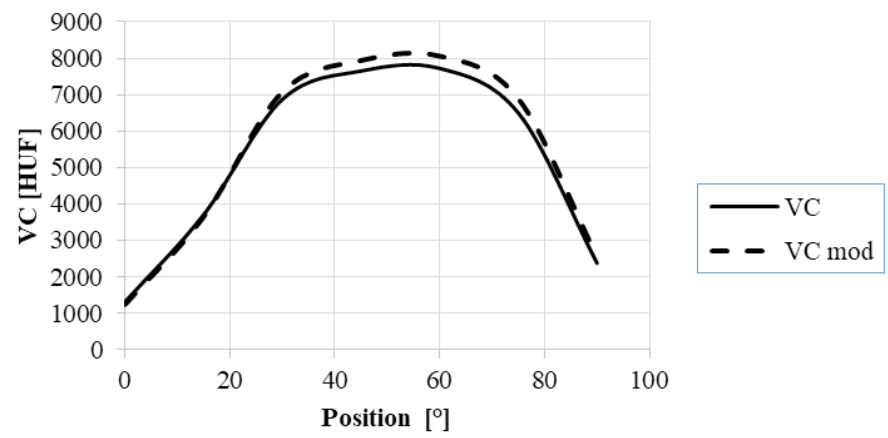

Fig. 9.

Variable Cost (VC) by Manufacturing Time $\left(C_{t}\right)$ and Raw Material Cost $\left(C_{m}\right)$, as well as Modified Raw Only, Cost (VC mod) depending on the component position

It can be clearly seen that by simplifying the cost calculation into a single component, we can still get almost the same result as the original one. This may simplify the pricing strategy without having to explain, where appropriate, why the unit price of a given material is so low that it can be bought at a lower cost by the retailer.

\section{Conclusion}

Summarising the experience, it can be concluded that determining the market price of a product is a very complex task. The price includes many other factors besides design and production costs that are difficult to quantify. These may include the benefits of an earlier entry, as well as the results of reduced error costs. Therefore, this study examines costs exclusively from the manufacturer's perspective and focuses exclusively on direct manufacturing costs. Even with these reductions, many factors can influence costs, so as a result of further reductions, we only analysed the impact of positioning and positioning the part on the workspace.
Analyses show that placement has a decisive influence on costs, as price variations can occur as a result. It can be concluded from the results that states close to horizontal and vertical are the most cost-effective arrangements.

It is important to emphasise that many factors in the manufacturing costs of additive technologies influence the possibility of individual production. This could also be a disadvantage (e.g. in the case of pricing), as each piece has different shape features. As a result, it is difficult to make general statements that are true to every piece. Because we can produce completely different geometries, even at the same time in the same workspace, processes cannot be standardised. However, it is advisable to develop a transparent pricing strategy that is understandable to the customer. The results described in this article help us to do this, and we can even make this relation one-variable, and we can determine the price. It is also important to note that when determining the need for raw material, the support material is also needed to be 
counted. However, since the amount of material is proportional to the production time, it is advisable to choose a production time-based strategy for pricing.

One of the prerequisites for the further spread of additive manufacturing technologies is to make it easier and more transparent for nonprofessionals to access.

\section{References}

Andrejszki, T.; Török, Á. 2018. New pricing theory of intelligent flexible transportation, Transport 33(1): 69-76.

Ficzere, P.; Borbás, L.; Torok, A. 2013. Economical investigation of rapid prototyping, International Journal for Traffic and Transport Engineering 3(3): 344-350.

Ficzere, P.; Borbás, L. 2018. Experimental Investigation of the Shear Modulus in the Case of Pure Tensile Test, Transactions of Famena 42(1): 27-36.

Ficzere, P.; Borbás, L.; Torok, A. 2012. Toyotarity in Rapid Prototyping. In Proceedings of Toyotarity: Toyota Management Principles' Interpretation in Different Branches, Czestochowa, Poland. Oficyna Wydawnicza Stowarzyszenia Menedzerów Jakosci i Produkcji, 159-169.

Ficzere, P. 2020. Experimental Dynamical Analysis and Numerical Simulation of the Material Properties of Parts Made by Fused Deposition Modelling Technologies, Periodica Polytechnica Transportation Engineering 48(3): 221-225.
Gvozdenović, S.; Mirosavljević, P. Vujić, A. 2005. Influence of delays on total costs in airline industry. In Proceedings of the $9^{\text {th }}$ Annual World Conference, Air Transport Research Society (ATRS) World Conference, Federal University of Rio de Janeiro, Brazil, July 3-6, 2005. 6p.

Győri, M.; Ficzere, P. 2017. Use of Sections in the Engineering Practice, Periodica Polytechnica Transportation Engineering 45(1): 21-24.

Hartman, J. 2019. Retooling the Engine. Available from Internet: <https://www.stratasys.com/resources/search/ case-studies/volvo-construction $>$.

Mirosavljević, P.; Gvozdenović, S.; Čokorilo, O. 2010. The transport aircraft pollution cost reduction strategy, FME Transactions 38(4): 157-166.

Stratasys. 2020. Available from Internet: <https:// www.stratasys.co.in/resources/search/case-studies/ volvo-construction>.

Torok, A.; Derenda, T.; Zanne, M.; Zoldy, M. 2018. Automatisation in road transport: a review, Production Engineering Archives 20(20): 3-7.

Zöldy, M.; Török, Á. 2015. Road transport liquid fuel today and tomorrow: a literature overview, Periodica Polytechnica Transportation Engineering 43(4): 172-176.

3dee. 2019. Available from Internet: $<$ https://3dee.at/3ddienstleistungen/3d-druck/>. (Accesed: 2019.05.02.). 